\title{
The expression of growth factor signaling genes in co-culture IVM
}

\author{
Erif Maha Nugraha Setyawan ${ }^{1, *}$, Hyun Ju Oh ${ }^{1}$, Min Jung Kim ${ }^{1}$, Geon A Kim ${ }^{1}$, Seok Hee Lee ${ }^{1}$, Yoo Bin Choi ${ }^{1}$, Ki Hae Ra ${ }^{1}$, \\ and Byeong Chun Lee ${ }^{1}$ \\ ${ }^{1}$ Department of Theriogenology and Biotechnology, College of Veterinary Medicine, Seoul National University, 1 Gwanak-ro, Gwanak-gu, \\ Seoul 08826, Republic of Korea \\ *Corresponding author: erifmaha@snu.ac.kr
}

\begin{abstract}
The objective of this study was to determine the expression of growth factor signaling genes in human adiposederived stem cells (ASCs), porcine oocytes, and cumulus during in vitro maturation (IVM). The human ASCs (from 2 young and 2 old donors) were used for the co-culture IVM system. The maturation rate was examined based on polar body extrusion. The expression of the growth factor signaling genes from ASCs, oocytes, and cumulus were measured using qPCR. All data were analyzed using ANOVA followed by Tukey's test. The expression of the h-IGF1 signaling genes from human ASCs cells showed similar values in all groups and the h-FGF2 expressions were higher in the young donors than the old ones. The p-FGF2, p-FGFR2, and p-TGFB1 expressions in the oocytes as well as p-IGFR in the cumulus that were co-cultured from the young donors showed higher values than the old and control groups. The apoptotic ratio ( $p-B A X / p-B C L 2)$ from the oocytes and cumulus in both co-culture groups also showed lower levels than the control $(P<0.05)$. Oocyte maturation rates were significantly increased in all co-cultured groups (Y1 (85.9 $\pm 2.2 \%), \mathrm{Y} 2(91.2 \pm 1.1 \%), \mathrm{O} 1(86.3 \pm 1.5 \%)$, and O2 (86.5 $\pm 2.3 \%)$ ) compared with the control $(76.7 \pm 1.1 \%$; $\mathrm{P}<0.05)$. Although the expression of growth factor signaling genes was varied, young donors' ASCs might support in vitro maturation better than those from old donors.
\end{abstract}

KEYWORDS co-culture; gene expression; human ASCs; oocytes maturation

\section{Introduction}

In vitro maturation (IVM) technique have been essential and important to retrieve high quality mature oocytes for optimum result in the further study, such as embryo production, xenotransplantation and animal model research (Woods and Tilly 2012; Coticchio et al. 2015; Arat et al. 2016). The oocyte is a unique and highly specialized cell responsible for creating, activating and controlling the embryonic genome, as well as supporting basic processes, such as cellular homeostasis, metabolism and cell cycle progression in the early embryo. Oocytes maturation were occurred when the oocytes reached nuclear and cytoplasmic maturation (Coticchio et al. 2015). Nuclear maturation encompasses numerous sequential events, including the breakdown of the germinal vesicle and the resumption of meiosis, the first meiotic division, and the appearance of second metaphase chromosomes. These processes can be evaluated cytologically by the appearance of the first polar body or metaphase II chromosomes (Machtinger et al. 2016). Cytoplasmic maturation occurs alongside of nuclear maturation, involving dramatic changes in oocyte gene expression, protein synthesis, and organelle organization (Woods and Tilly 2012; Machtinger et al. 2016).
Cumulus cells have been considered to play an important role in oocyte maturation by keeping the oocyte under meiotic arrest, inducing meiotic resumption and by supporting cytoplasmic maturation. These functions have been attributed to their gap junctions and their specific metabolizing capabilities. Physical contact between oocyte and cumulus cells has been considered necessary for the transfer of nutrients and factors essential for oocyte development (Hull and Harvey 2014).

The IVM conditions are still suboptimal for oocyte maturation (Woods and Tilly 2012; Coticchio et al. 2015). To optimize the IVM conditions, many studies have applied several growth factors and cell feeding/co-culture systems using various cell types to restore the follicular microenvironment during IVM (Uzumcu et al. 2006; Toori et al. 2014). Growth factors are a component of a complex system of autocrine and paracrine factors that have a regulatory role in ovarian function and affect oocyte maturation (Arat et al. 2016). The in vitro administration of exogenous growth factors were also reported in many species (e.g., bovine, canine, ovine, and equine) that could accelerate nuclear maturation and increase the percentage of oocytes resuming meiosis (Hull and Harvey 2014). IGF1 was of benefit for oocyte maturation and preimplan- 
tation development by autocrine stimulation of cumulus and/or granulosa cells in pigs and similar results have been reported in mice and cattle (Arat et al. 2016). Members of the TGF $\beta$ superfamily, including TGF $\beta 1$, TGF $\beta 3$, bone morphogenetic protein 15 (BMP15) and growth differentiation factor 9 (GDF9), are expressed in the oocyte from very early stages and are responsible for oocyte maturation (da Silveira et al. 2014). Further, few studies have focused on the effects of exposure to a combination of growth factors on oocyte IVM (Arat et al. 2016), but the co-culture system also chosen to support the IVM condition (Saadeldin et al. 2014; Appeltant et al. 2016).

Adipose-derived stem cells (ASCs) The potential candidate of secrete high levels of several growth factors which have roles on oocytes maturation such as insulinlike growth factor (IGF), basic fibroblast growth factor (bFGF), vascular endothelial growth factor (VEGF), hepatocyte growth factor (HGF) and transforming growth factor-beta (TGF- $\beta$ ) (Fu et al. 2008; da Silva Meirelles et al. 2009; Overman et al. 2013). ASCs exhibit stable growth and proliferation kinetics and can differentiate toward osteogenic, chondrogenic, adipogenic, myogenic, or neurogenic lineages in vitro (Scruggs et al. 2013; Shimada et al. 2006) which has potential as cell feeder in co-culture system. But biologic aging also occurs in stem cells which was shown with secrete less growth factors and other bioactive molecules (Scruggs et al. 2013). Those reports showed the important of donor age that should be considered when select ASCs as cell feeder in co-culture system. To gain insight into effectivity of co-culture system using different donor age of ASCs on porcine IVM, the maturation rate and expression of growth factor signaling genes and some receptors on ASCs, oocytes and cumulus were evaluated. Our hypothesis was that the activity of ASCs in co-culture IVM system would enhance the interaction between oocytes and cumulus which increase the oocytes maturation rate.

\section{Materials and methods}

All chemicals were obtained from Sigma-Aldrich Co. LLC. (St. Louis, USA) unless otherwise stated. The young donors of ASCs came from 2 peoples under 30 years old and the old donors also came from 2 peoples with aged more than 50 years old.

\subsection{Isolation and culture of ASCs}

The procedure for preparation of human ASCs was performed under GMP conditions in the Stem Cell Research Center of R Bio, with approval from the Life Ethics Committee of the Biostar Stem Cell Technology, Seoul, Republic of Korea (RBIO 2015-12-001). The ASCs were isolated from disposed human adipose tissues obtained from the lower abdomen of patients with their agreement and primary cultured as previously described (Ra et al. 2011). In detail, human subcutaneous adipose tissues were obtained by simple liposuction from abdominal subcutaneous fat with informed consent and digested with collagenase I $(1 \mathrm{mg} / \mathrm{mL})$ under gentle agitation for $60 \mathrm{~min}$ at $37^{\circ} \mathrm{C}$. The digested tissues were then filtered through a $100-\mu \mathrm{m}$ nylon sieve. The tissues were centrifuged at $470 \mathrm{~g}$ for $5 \mathrm{~min}$ and resuspended in Dulbecco's modified Eagle's medium (DMEM; Invitrogen)-based medium containing $0.2 \mathrm{mM}$ ascorbic acid and $10 \%$ fetal bovine serum (FBS). After re-centrifuging at $470 \mathrm{~g}$ for $5 \mathrm{~min}$, the supernatant was discarded and the cell pellet was collected. These cells were cultured overnight at $37^{\circ} \mathrm{C}$ under $5 \%$ $\mathrm{CO}_{2}$ in DMEM-based medium containing $0.2 \mathrm{mM}$ ascorbic acid and 10\% FBS. The cell medium was changed to Keratinocyte-SFM (Invitrogen)-based medium containing $0.2 \mathrm{mM}$ ascorbic acid, $0.09 \mathrm{mM}$ calcium, $5 \mathrm{ng} / \mathrm{mL}$ rEGF and 5\% FBS. The cells were maintained for $4-5 \mathrm{~d}$ until confluent (passage 0 ). When the cells reached $90 \%$ confluency, they were subculture-expanded in KeratinocyteSFM-based medium containing $0.2 \mathrm{mM}$ ascorbic acid, $0.09 \mathrm{mM}$ calcium, $5 \mathrm{ng} / \mathrm{mL}$ rEGF and 5\% FBS until passage 3. FBS contaminants were completely removed from cultured MSCs by several washings with PBS and verified through a test of albumin level below the measurement limit using a bovine albumin ELISA kit (Bethyl Laboratories, Montgogery, TX). The Korea Food and Drug Administration permitted the use of FBS-eliminated MSCs for clinical study. Aliquots of the ASCs were then tested for cell viability and fungal, bacterial, endotoxin and mycoplasma contamination as demanded by the Code of Federal Regulations, Title 21 (21CFR) before further use. The details of specific standards are found in the 21CFR, Sections 610. There was no chromosomal abnormality in any sample up to passage 12 .

\subsection{In vitro maturation of porcine oocytes by co- culture with human ASCs}

Ovaries were obtained from sows and gilts at a local slaughterhouse and transported to the laboratory in $0.9 \%$ $\mathrm{NaCl}$ at $25-30^{\circ} \mathrm{C}$. Follicular fluid including cumulusoocyte complexes (COCs) were aspirated from antral follicles (3-6 mm in diameter) and washed three times with tissue culture medium-199 (TCM-199)-HEPES (Invitrogen, Carlsbad, USA) and selected for in vitro maturation on the basis of morphological features, i.e., a compact multi-layered cumulus mass and a dark, evenly granulated cytoplasm. The COCs were cultured in four-well dishes (50 COCs per well; Falcon, Becton Dickinson Ltd, Plymouth, UK) in basic maturation medium, TCM199 supplemented with $10 \mathrm{ng} / \mathrm{mL}$ epidermal growth factor (EGF), $0.57 \mathrm{mM}$ cysteine, $0.91 \mathrm{mM}$ sodium pyruvate, $5 \mu \mathrm{g} / \mathrm{mL}$ insulin, $1 \mu \mathrm{g} / \mathrm{mL}$ follicle-stimulating hormone (FSH) (Antrin, Teikoku, Japan), and 1\% (vol/vol) penicillin-streptomycin (Pen-Strep; Invitrogen) at $39^{\circ} \mathrm{C}$ in a humidified atmosphere of $5 \% \mathrm{CO}_{2}$ for $44 \mathrm{~h}$ (two stages, with hormonal removal in the second stage). After $44 \mathrm{~h}$, oocytes and expanded cumulus cells were separated by 
pipetting with $0.1 \%$ hyaluronidase in Tyrode's albumin lactate pyruvate (TALP). Denuded oocytes were examined by microscope free of any attached somatic cells and then were subjected to observe the first polar body extrusion.

Porcine ovaries were obtained from sows at a local slaughterhouse and transported to the laboratory in $0.9 \%$ $\mathrm{NaCl}$ at $30-35^{\circ} \mathrm{C}$ within $3 \mathrm{~h}$. The follicular fluid including cumulus-oocyte complexes (COCs) were aspirated from 3-6 mm diameter follicles with an 18-gauge needle on a $10 \mathrm{~mL}$ syringe and washed three times in washing medium containing $9.5 \mathrm{~g} / \mathrm{L}$ of TCM-199, 2 mM sodium bicarbonate, $10 \mathrm{mM}$ HEPES, $0.3 \%$ polyvinyl alcohol, $5 \mathrm{mM}$ sodium hydroxide and 1\% penicillin-streptomycin (Invitrogen) as previously reported (Jin et al. 2016). COCs were selected on the basis of morphological features: three or more compact multilayers of cumulus cells and homogeneous cytoplasm. Around 5060 COCs per well were cultured in IVM medium containing TCM-199 supplemented with $10 \mathrm{ng} / \mathrm{mL}$ Epidermal growth factor (EGF), $0.57 \mathrm{mM}$ cysteine, $0.91 \mathrm{mM}$ sodium pyruvate, $5 \mu \mathrm{l} / \mathrm{mL}$ insulin-transferrin-selenium solution 100X (Invitrogen), $10 \%$ porcine follicular fluid, $10 \mathrm{IU} / \mathrm{mL}$ equine chorionic gonadotropin (eCG), and $10 \mathrm{IU} / \mathrm{mL}$ human chorionic gonadotropin (hCG) in a 12-well plate (Falcon).

In order to perform co-culture experiments, young and old donor ASCs were used when they had reached about $70 \%$ confluency in a 12-well plate with AMSC medium (Rmedica-stemcell, Korea). The medium was replaced with IVM medium when co-culture began. The 12-well plates were supported with $1.0 \mu \mathrm{m}$ Transwell polyester membrane inserts (Corning Inc., Pittston, USA) to allow mutual communication (Saadeldin et al. 2014) between porcine oocytes and ASCs for a total of $44 \mathrm{~h}$ at $39^{\circ} \mathrm{C}$ in a humidified atmosphere of $5 \% \mathrm{CO}_{2}$ in IVM medium. The intercellular communication distance was approximately
$2 \mathrm{~mm}$. The COCs were randomly allocated to young or old ASCs co-culture groups on Transwell polyester membrane inserts or cultured in IVM medium only (control group). The control group was maintained under the same conditions as the co-culture groups except for the ASCs support. The control and co-culture groups were cultured for $22 \mathrm{~h}$ with $10 \mathrm{IU} / \mathrm{mL}$ eCG and then washed twice in eCG-free medium. Afterwards, the co-culture cells and/or COCs were cultured for $22 \mathrm{~h}$ in IVM medium without eCG. After $44 \mathrm{~h}$ culture for IVM, the COCs were denuded with $0.1 \%$ hyaluronidase by gently pipetting and cumulus cells were separated from COCs by centrifugation ( $2 \mathrm{~min}, 1,975$ g) and the samples were immediately stored at $-80^{\circ} \mathrm{C}$ until used for RNA extraction. For assessing in vitro maturation rates, extrusion of the first polar body (Metaphase II) was evaluated under the stereomicroscope and ASCs from the co-culture groups were retrieved for total RNA extraction.

\subsection{Total RNA extraction and cDNA synthesis}

Total RNA was extracted from ASCs (young and old donors), cumulus and oocytes using the Easy-spinTM (DNA-free) Total RNA Extraction Kit (iNtRON Biotechnology Inc., Kyunggi, Korea) then eluted according to the manufacturer's protocol. Total RNA concentration was measured using spectrophotometry (NanoDrop 2000, Thermo Fisher Scientific Inc, Waltham, USA), with samples immediately stored at $-80^{\circ} \mathrm{C}$ until cDNA synthesis. Total RNA was reverse transcribed into cDNA using amfiRivert II cDNA Synthesis Premix (GenDEPOT, Barker, USA) according to the manufacturer's instructions.

\subsection{Gene expressions analysis using real-time poly- merase chain reaction PCR}

Quantitative real-time PCR (qPCR) was conducted to assess the transcript abundance using oligonucleotide primer

TABLE 1 Primer sequences used for gene expression analysis in human.

\begin{tabular}{|c|c|c|c|}
\hline Gene & Primer sequences $\left(5^{\prime}->3^{\prime}\right)$ & Product size (bp) & GenBank no. \\
\hline \multirow[t]{2}{*}{ ACTH } & F- GCCGAGGACTTTGATTGCAC & 145 & NM_001101.3 \\
\hline & R- TGTGTGGACTTGGGAGAGGA & & \\
\hline \multirow[t]{2}{*}{ IGF1 } & F- ATGTATTGCGCACCCCTCAA & 119 & NM_000618.4 \\
\hline & R- GCACTCCСTCTACTTGCGTT & & \\
\hline \multirow[t]{2}{*}{ FGF2 } & F- AAGCAGGAGGATCGCTTGAG & 110 & NM_002006.4 \\
\hline & R- GAGACCACATGTACACGCCA & & \\
\hline \multirow[t]{2}{*}{ VEGFA } & F- TCTCCСTGATCGGTGACAGT & 107 & NM_001025366.2 \\
\hline & R- AAGGAATGTGTGCTGGGGAG & & \\
\hline \multirow[t]{2}{*}{ HGF } & F- AAGGCCAAGTCCCCAAACAA & 111 & NM_000601.5 \\
\hline & R- TCGCCGCCCTATATTCTGTG & & \\
\hline \multirow[t]{2}{*}{ TGF $\beta 1$} & F- TACCAGATCGCGCCCATCTA & 136 & NM_000660.5 \\
\hline & R- TCTCCCGGCAAAAGGTAGGA & & \\
\hline \multirow[t]{2}{*}{ TGF $\beta 3$} & F- AGTTCCTGGCCCATCAACTG & 149 & NM_003239.3 \\
\hline & R- GGCGTCTAACCAAGTGTCCA & & \\
\hline
\end{tabular}


TABLE 2 Primer sequences used for gene expression analysis in pigs.

\begin{tabular}{|c|c|c|c|}
\hline Gene & Primer sequences $\left(5^{\prime}\right.$-> $\left.3^{\prime}\right)$ & Product size (bp) & GenBank no. \\
\hline \multirow[t]{2}{*}{ GAPDH } & F: CTTCCACTTTTTGATGCTGGGG & 145 & NM_001206359.1 \\
\hline & R: TCCAGGGGCTCTTACTCCTT & & \\
\hline \multirow[t]{2}{*}{ BAX } & F: CCCGAACTGATCAGGACCAT & 108 & XM_003127290 \\
\hline & R: AAAGTAGGAGAGGAGGCCGT & & \\
\hline \multirow[t]{2}{*}{$\mathrm{BCL} 2$} & F: GGGAGCTGGTGGTTGACTTT & 138 & NM_214285 \\
\hline & R: TGATGGCACTAGGGGTTTCC & & \\
\hline \multirow[t]{2}{*}{ BMP15 } & F: AGCTCTGGAATCACAAGGGG & 123 & NM_001005155.1 \\
\hline & R: ACAAGAAGGCAGTGTCCAGG & & \\
\hline \multirow[t]{2}{*}{ GDF9 } & F: ACATGACTCTTCTGGCAGCC & 140 & NM_001001909.1 \\
\hline & R: ACCCTCAGACAGCCCTCTTTT & & \\
\hline \multirow[t]{2}{*}{ IGF1 } & F: TGGTGGACGCTCTTCAGTTC & 145 & NM_214256.1 \\
\hline & R: TCCAGCCTCCTCAGATCACA & & \\
\hline \multirow[t]{2}{*}{ FGFR2 } & F: TCATCTGCCTGGTTGTGGTC & 140 & NM_001099924.2 \\
\hline & R: CGCAGCCACGTAAACTTCTG & & \\
\hline \multirow[t]{2}{*}{ FGF2 } & F: AGGAGTGTGTGCAAACCGTT & 124 & XM_013978917.1 \\
\hline & R: CACAACAGGATCAGGCCAGA & & \\
\hline \multirow[t]{2}{*}{ IGF1R } & F: CCCAATGGCAACCTGAGCTA & 137 & NM_214172.1 \\
\hline & R: TCCTCGACATCAATGGTGCC & & \\
\hline \multirow[t]{2}{*}{ TGFß1 } & F: TTCTGGTGGGGAGACAGACA & 139 & NM_214015.2 \\
\hline & R: CCTAGGCTGCTTTCTTGGCT & & \\
\hline \multirow[t]{2}{*}{ TGFß3 } & F: AAAGCGATACACAGCCACGA & 115 & ENSSSCG00000002385 \\
\hline & R: AGCCTCCCTCCTGTCTTGAT & & \\
\hline
\end{tabular}

sequences in human and porcine. The primers for human (BAX, BCl2, IGF1, FGF2, VEGFA, HGF, TGF 1 , TGF $\beta 3$ and $\beta$-actin) and porcine (BAX, BCl2, BMP15, GDF9, IGF1, IGF1R, FGF2, FGFR2, TGF 1 , TGF 33 and GAPDH) genes were designed from sequences which obtained from NCBI; all primer sequences were standardized using a standard curve and are listed in Tables 1 and 2. Real-time PCR was performed using an ABI 7300 Real Time PCR System (Applied Biosystems, Foster City, USA) according to the manufacturer's instructions with minor modification. The total volume PCR reaction mixture was $20 \mu \mathrm{L}$ in a real-time PCR plate (MicroAmp optical 96-well reaction plate, Singapore) and the mixture was composed of $2 \mu \mathrm{L}$ cDNA, $0.4 \mu \mathrm{L}$ forward primer, $0.4 \mu \mathrm{L}$ reverse primer, $10 \mu \mathrm{L}$ SYBR Green interaction dye (Takara Bio USA Inc., Mountain View, USA) and 7.2 $\mu \mathrm{L}$ diethyl pyrocarbonate. The expression of each target gene was quantified relative to that of the internal control gene (ACTB) using the equation $R=2^{-[\Delta C t \text { sample }-\Delta C t \text { control }]}$, as previously described by Setyawan et al. (2016).

\subsection{Statistical methods}

All data were analyzed by one-way ANOVA then followed by Tukey's multiple comparison test using GraphPad Prism 5.0 (GraphPad, San Diego, USA) (Setyawan et al. 2016). Values are means \pm standard error of the mean. Probability values less than 0.05 were considered to be statistically significant.

\section{Results}

\subsection{The expression of signaling genes in human ASCs}

The h-IGF1, h-FGF2, h-VEGFA, h-HGF, h-TGF $\beta 1$ and hTGF $\beta 3$ gene expression levels in four groups of human ASCs were analyzed (Y1, young donor 1; Y2, young donor 2; O1, old donor 1 and O2, old donor 2). There was no significant difference in levels of expression in IGF1 among the all groups (Figure 1). The Y1 and Y2 groups showed higher FGF2 gene expression levels compared with the $\mathrm{O} 1$ and $\mathrm{O} 2$ groups but HGF levels seemed higher in $\mathrm{O} 2$ than $\mathrm{Y} 1$ and $\mathrm{Y} 2$. The $\mathrm{O} 2$ expressed the lowest expression in VEGF than other groups. The $\mathrm{O} 1$ showed the lowest expression in TGF $\beta 1$ and TGF $\beta 3$ compared with the other three groups.

\subsection{The expression of genes related to oocytes matu- ration in porcine cumulus cells}

The relative expression of genes related to oocyte maturation and apoptosis was analyzed in porcine cumulus cells derived from COCs after IVM without co-culture (control) or with co-culture using ASCs (Y1, Y2, O1 and O2). The 

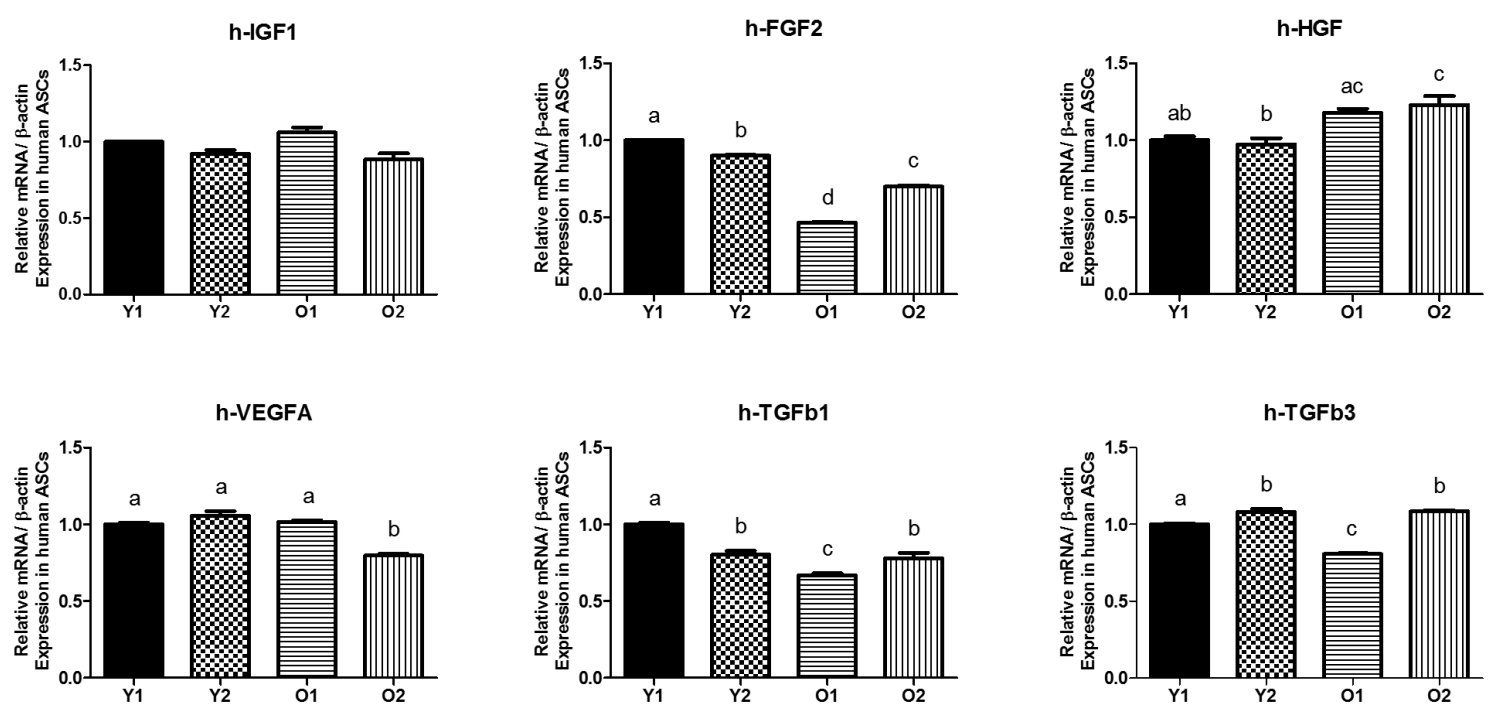

FIGURE 1 The expression of growth factor signaling genes from human adipose-derived stem cells (ASCs). Y1, young donor 1; Y2, young donor 2; O1, old donor 1; O2, old donor 2.

ratio of apoptotic gene expression (p-BAX / p-BCL2) in co-cultured groups showed significantly lower than control. The co-cultured groups also significantly up regulated p-IGF1, p-IGF1R, p-FGF2, p-FGFR2, p-TGF $\beta 1$ and p-TGFß3 expression compared with control group. The old donor groups showed lower expression in p-IGF1R and $\mathrm{p}$-TGF $\beta 3$ than young donor groups. The other gene expressions among co-cultured groups exhibited different levels but still higher than control (Figure 2).

\subsection{The expression of genes related to maturation in porcine oocytes}

The relative gene expression levels of SMAD2/3 and GDF9 in matured porcine oocytes derived from each group were analyzed. The expression of p-IGF1 among co-cultured groups were not different but significantly higher than control $(\mathrm{P}>0.05)$. Its receptor (p-IGF1R) also showed higher expression in co-cultured group than control but exhibited different level of expression among cocultured groups (Figure 3). The expression of p-FGF2 and p-FGFR2 showed similar pattern that the significant differences only found in young groups ( $\mathrm{Y} 1$ and $\mathrm{Y} 2$ ) but there were no different between $\mathrm{O} 1, \mathrm{O} 2$ and control groups. The high expression in young groups were also showed in $\mathrm{p}$ TGF $\beta 1$ which significantly different with old groups and all co-cultured groups were higher than control. Interestingly, the expression of p- TGF $\beta 3$ in control and cocultured groups were not significantly different.

\subsection{The effect of human ASCs co-culture on porcine oocyte maturation}

The effects of ASCs co-culture on the nuclear maturation of porcine oocytes was observed as shown in Table 3. The nuclear maturation rates in young ASCs groups ( $\mathrm{Y} 1=85.9$ $\pm 2.2 \%$ and $\mathrm{Y} 2=91.2 \pm 1.1 \%$ ) and old ASCs groups (O1
$=86.3 \pm 1.5 \%$ and $\mathrm{O} 2=86.5 \pm 2.3 \%$ ) were significantly higher than those in the control group (76.7 $\pm 1.1 \%$, $\mathrm{p}<$ 0.05 ). There were not differences between Y1, Y2, O1 and $\mathrm{O} 2$ groups in the oocyte maturation rate.

\section{Discussion}

Optimum condition of IVM system is required for successful and reliable oocyte maturation which would significantly improve the effectiveness of further development. Several studies have indicated that growth factors are beneficial for oocyte maturation in vitro because of the paracrine pathway (Shimada et al. 2006). Aging is known to have a negative impact on the regenerative capacity of most tissues and human ASCs are susceptible to biologic aging (Wu et al. 2013), including changes in differentiation potential, proliferation ability, and gene expression (Pandey et al. 2011). Herein we demonstrated that the expression of growth factors signaling gene in co-culture system using young and old donor of human ASCs during IVM could improve the porcine oocyte maturation.

The expression of signaling genes in human ASCs (Figure 1) were in line with the expression in human and murine bone marrow derived stem cells that older donor MSCs have decreased gene expression compared with younger donor (Wilson et al. 2010). Higher expression of HGF in $\mathrm{O} 2$ and similar expression value in some groups expressed that there were individual variation between donors but mostly younger donor seems a little higher than older donor. Those various different expression in RNA levels between young and old ASCs were also reported by Scruggs et al. (2013). After co-cultured with human ASCs in IVM system, the expression of all genes in cumulus (Figure 2) were significantly increased and apoptotic ratio also lower than control. Those benefit effects lead to increase the bidirectional communication between oocytes 

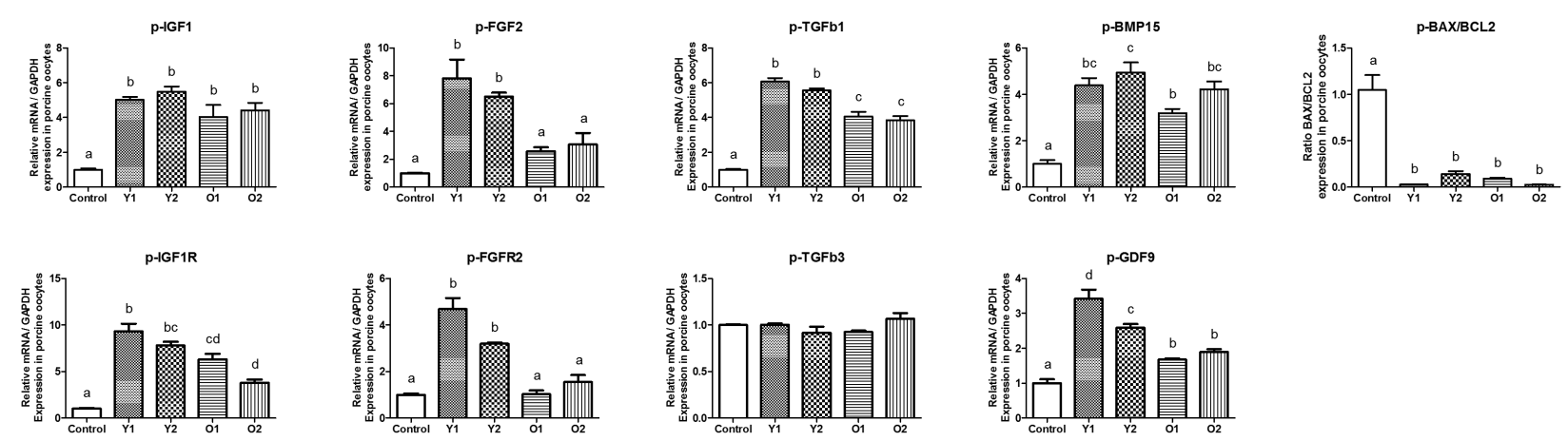

FIGURE 2 The expression of growth factor signalling genes from porcine oocytes after in vitro maturation (IVM). Control, without human adipose-derived stem cells (ASCs); Y1, young donor 1; Y2, young donor 2; O1, old donor 1; O2, old donor 2.
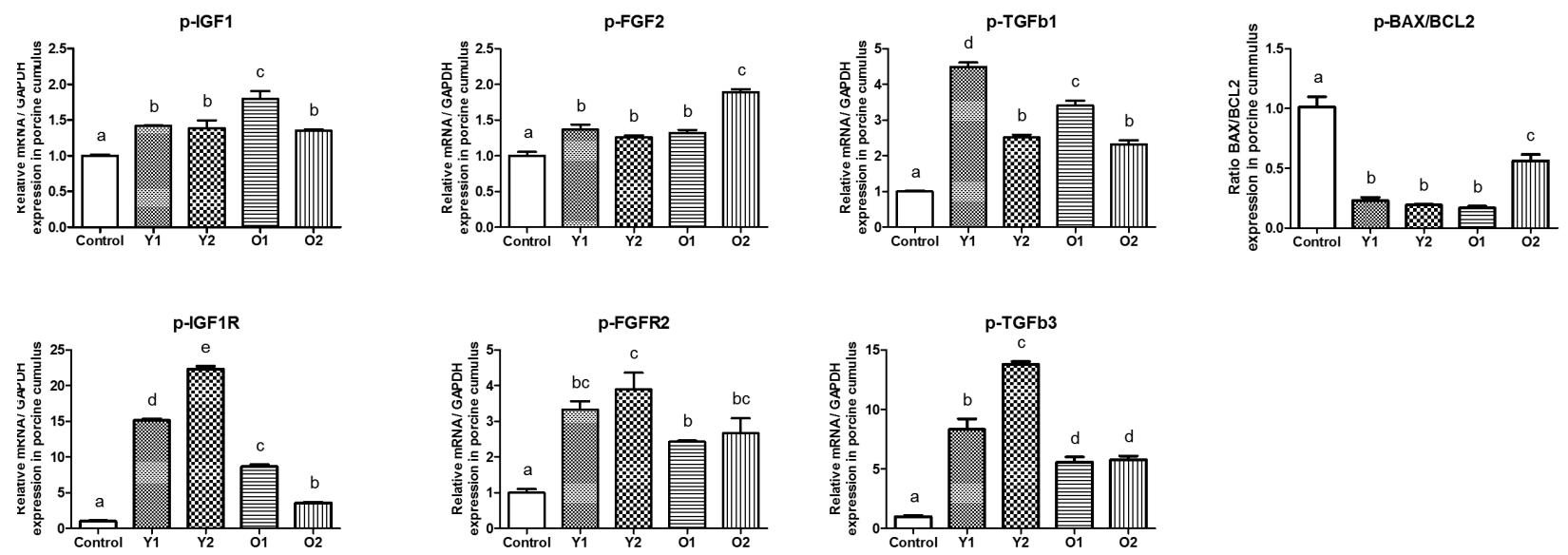

FIGURE 3 The expression of growth factor signaling genes from porcine cumulus after in vitro maturation (IVM). Control, without human adipose-derived stem cells (ASCs); Y1, young donor 1; Y2, young donor 2; O1, old donor 1; O2, old donor 2.

and cumulus in order to enhance nuclear and cytoplasmic maturation in oocytes (Appeltant et al. 2015). The exogenous growth factors addition also reported in rats which affected in modulating cumulus cell expansion, stimulating proliferation and inhibiting apoptosis (Arat et al. 2016). The exact role of cumulus during the initiation of meiotic resumption in pigs has been a matter of debate that the signal coming from cumulus as a key factor for triggering meiosis in oocytes (Gilchrist 2011) and others suggested that a cumulus-secreted soluble factor(s) may be responsible for the reinitiation of nuclear progression in oocyte during IVM (Appeltant and others 2015). Our result revealed that, the higher activity of cumulus that showed by higher gene expression in co-culture IVM system with any donor age of ASCs could support oocytes maturation more than control group. Those high activities could be supported by growth factors and other bioactive molecules from ASCs via extracellular vesicles (Machtinger et al. 2016).

The growth factors from human ASCs played many roles in oocytes maturation and the high expression of those signaling gene in oocytes (Figure 3) showed their activities in several pathways. citemachtinger2016 reported that growth factors could escalate oocyte maturation in mammals by accelerate several mechanism related with wingless signaling pathway (WNT), transform- ing growth factor beta (TGFb), mitogen-activated protein kinase (MAPK), neurotrophin, epidermal growth factor receptor (ErbB) pathways and ubiquitin-mediated pathways (Hull and Harvey 2014). Our result revealed that the percentage of oocytes reached the MII stage under the coculture IVM system with any donor age of ASCs showed a significantly higher compared with control. Those result suggested that the growth factors and other bioactive molecules from ASCs supported cumulus and also directly to oocytes activities which would give the optimum meiosis and nuclear progression in oocytes during IVM.

The significant different between control group and co-culture groups in maturation rate (Table 3) showed that the use of co-culture in IVM system allowed the growth factors which were secreted by ASCs could stimulate the oocytes maturation including nuclear and cytoplasmic maturation and also increase the effectiveness of IVM. Similar result also reported in many species (e.g., bovine, canine, ovine, and equine) that the administration of exogenous growth factors during IVM could accelerate nuclear maturation and increase the percentage of oocytes resuming meiosis citephull2014. The incubation of in vitro bovine and equine oocytes with growth factors significantly escalated cytoplasmic maturation by increased the cortical redistribution (Pereira et al. 2013). 
TABLE 3 Evaluation of in vitro maturation rate of porcine oocytes co-cultured with adipose-derived stem cells (ASC) young and old donors.

\begin{tabular}{lll}
\hline Group & No. of oocytes cultured & $\begin{array}{l}\text { No. oocytes of with } \\
\text { first polar body ex- } \\
\text { trusion (\%) }\end{array}$ \\
\hline Control & 331 & $253(76.7 \pm 1.1)^{\mathrm{a}}$ \\
Y1 & 335 & $286(85.9 \pm 2.2)^{\mathrm{b}}$ \\
Y2 & 272 & $247(91.2 \pm 1.1)^{\mathrm{b}}$ \\
O1 & 332 & $285(86.3 \pm 1.5)^{\mathrm{b}}$ \\
O2 & 272 & $233(86.5 \pm 2.3)^{\mathrm{b}}$
\end{tabular}

$\mathrm{a}, \mathrm{b}$ Within a column, values with different superscript letters are significantly different $(p<0.05)$. Experiment was replicated at least seven times.

In the present study, the contributions of young and old donor of ASCs to oocyte maturation and gene expression were analyzed under same culture conditions between coculture groups with control. Our study demonstrated that co-culturing with young and old donor of ASCs were essential for oocytes to achieve higher nuclear and cytoplasmic maturation rates, and this would allow their development competence to improve in the next stages.

The expression of IGF1 in co-culture groups were significantly increased when compared with control but there were no significant different between treatment groups. The respond in oocytes showed higher level than in cumulus compared with control after co-culture with ASCs (Figure 1). The IGF1R expression in oocytes and cumulus also showed the similar pattern that co-culture groups expressed more than control but cumulus showed higher expression than oocytes compare with each control. Interestingly, Young donor (Y1 and Y2) resulted higher level than old donor (O1 and O2) which were showed in Figure 2 and Figure 3. These result demonstrated that COCs have more IGF1 and IGF1R activities during co-cultured with human ASCs which could support maturation rate. This mechanism already reported that IGF1 have an important role in the nuclear maturation and cytoplasmic maturation of oocytes, exert its effect through cumulus cells by regulation of porcine cumulus proliferation and suppressed apoptosis (Toori et al. 2014). The IGF1R is activated by locallyproduced or circulating IGF1 which leads to autophosphorylation of the tyrosine kinase domain, with ensuing activation of the Ras-Raf-MAP kinase and PI3K-PKB/Akt signaling pathways and exert its mitogenic and antiapoptotic activities (Bentov and Werner 2011).

The FGF2 and FGFR2 expressions from oocytes and cumulus in all treatment groups were significantly higher than each control group. Young donor in oocytes showed more expression value of FGF2 and FGFR2 compared with both expressions in cumulus (Figure 3). Higher expression also founded in BPM15 and GDF9 from oocytes and only GDF9 showed that young donor expressed higher level than old donor. The expression of FGF2 and FGFR2 in all treatment groups from cumulus also showed significant difference compared to each control group. Those growth factors and receptors together modulated the maturation process in IVM. The FGF2 activity enhances the maturation of mammalian cumulus-oocyte complexes (COCs) by increasing the expression of cumulus cell expansion-related genes in pigs (Son et al. 2017). The FGF2 receptors (FGFR2) can be utilized between cumulus cells and oocytes (Pomini Pinto et al. 2015). BMP15 and GDF9 plays a role in oocyte maturation by binding with various TGF-beta receptors leading to activate MAPK pathways for cumulus expansion/oocyte activation and FGF) cooperate with BMP15 promote glycolysis in cumulus cell (Son et al. 2017). BMP15 belongs to the TGF- $\beta$ superfamily and is known as a granulosa cell mitosis and proliferation inducer. The production of adequate amounts of BMP15 protein by the oocyte is necessary to promote cumulus cells expansion. The expression of BMP15 mRNA was also found in cumulus cells and it decreased along with the oocyte maturation and cumulus expansion in vitro (Bogacki et al. 2014).

The TGF $\beta 1$ in oocytes showed that young donor expressed higher value than old donor groups and exhibited various expression in cumulus but still higher than control group. The expression of TGFß3 in oocytes (Figure 2) showed similar value but the high respond was founded in cumulus (Figure 3) that young donor group exhibited significant different compared with old donor groups and all treatment groups had significant different with control group. Both growth factors could activate MAPK pathways which crucially involved in the processes of oocyte development and TGF $\beta 1$ have more influence than TGF $\beta 3$ in cumulus expansion and oocytes activation (Machtinger et al. 2016). Hepatocyte growth factor (HGF) promote anti-apoptotic on porcine cumulus cells (Uzumcu et al. 2006). Vascular endothelial growth factor A (VEGFA) improves quality of matured porcine oocytes (Arat et al. 2016) and contributes in regulation of crucial processes for prematurasional growth, differentiation, and development of oocytes (Kranc et al. 2017).

The co-culture system can create a microenvironment through secretion of autocrine and paracrine factors to the media (Saadeldin et al. 2014). In this study, we found that co-culture with human ASCs can support and improve the oocytes maturation when compared to the control group. Even though there were various expression in growth factor signaling genes between young and old donor ASCs, the growth factor secretions from both donors could increase the mRNA profiles in oocytes and cumulus which would contribute in nuclear and cytoplasmic maturation.

\section{Conclusions}

The lower ratio of BAX/BCL2 expression and higher expression of IGF1, IGF1R, FGF2, FGFR2, TGF $\beta 1$, TGF 33 , BMP15 and GDF9 in treatment groups compared with 
control group indicated that the co-culture IVM system using human ASCs could enhance the interaction between oocytes and cumulus which increase the oocytes maturation rate. The expression of growth factors signaling genes from young and old donor ASCs seems various between samples and not affect the maturation rate among co-culture treatment groups. There is a critical need for further studies in human ASCs to provide conclusive experimental evidence in cellular communication mediated by extracellular vesicles which might be contributed to oocyte maturation and embryo development.

\section{Acknowledgments}

This study was supported by Korea IPET (\#114059-03-3SB010), Nature Cell (\#550-20150030), Research Institute for Veterinary Science, and the BK21 plus program.

\section{Authors' contributions}

EMNS, HJO, MJK, BCL designed the study. EMNS, SHL, YBC, KHR carried out the laboratory work. EMNS, MJK, GAK, BCL analyzed the data. PK, BTF, GH, MJ, DW wrote the manuscript. All authors read and approved the final version of the manuscript.

\section{Competing interests}

None of the authors have any competing interests.

\section{References}

Appeltant R, Somfai T, Kikuchi K, Maes D, Van Soom A. 2016. Influence of co-culture with denuded oocytes during in vitro maturation on fertilization and developmental competence of cumulus-enclosed porcine oocytes in a defined system: co-culture with denuded oocytes. Anim Sci J. 87(4):503-510. doi:10.1111/asj.12459.

Appeltant R, Somfai T, Nakai M, Bodó S, Maes D, Kikuchi K, Van Soom A. $2015 . \quad$ Interactions between oocytes and cumulus cells during in vitro maturation of porcine cumulus-oocyte complexes in a chemically defined medium: effect of denuded oocytes on cumulus expansion and oocyte maturation. Theriogenology 83(4):567-576. doi:10.1016/j.theriogenology.2014.10.026.

Arat S, Caputcu AT, Cevik M, Akkoc T, Cetinkaya G, Bagis H. 2016. Effect of growth factors on oocyte maturation and allocations of inner cell mass and trophectoderm cells of cloned bovine embryos. Zygote 24(04):554-562. doi:10.1017/S0967199415000519.

Bentov Y, Werner H. 2011. IGF1R (insulin-like growth factor 1 receptor). Atlas Genet Cytogenet Oncol Haematol. (8). doi:10.4267/2042/44533.

Bogacki M, Wasielak M, Kitewska A, Bogacka I, Jalali B. 2014. The effect of hormonal estrus induction on maternal effect and apoptosis-related genes expression in porcine cumulus-oocyte complexes. Reprod Biol Endocrinol. 12(1):32. doi:10.1186/1477-7827-12-32.

Coticchio G, Dal Canto M, Mignini Renzini M, Guglielmo MC, Brambillasca F, Turchi D, Novara PV, Fadini R. 2015. Oocyte maturation: gamete-somatic cells interactions, meiotic resumption, cytoskeletal dynamics and cytoplasmic reorganization. Hum Reprod Update 21(4):427-454. doi:10.1093/humupd/dmv011.

da Silva Meirelles L, Fontes AM, Covas DT, Caplan AI. 2009. Mechanisms involved in the therapeutic properties of mesenchymal stem cells. Cytokine Growth Factor Rev. 20(5-6):419-427. doi:10.1016/j.cytogfr.2009.10.002.

da Silveira JC, Carnevale EM, Winger QA, Bouma GJ. 2014. Regulation of ACVR1 and ID2 by cell-secreted exosomes during follicle maturation in the mare. Reprod Biol Endocrinol. 12(1):44. doi:10.1186/14777827-12-44.

Fu X, He Y, Xie C, Liu W. 2008. Bone marrow mesenchymal stem cell transplantation improves ovarian function and structure in rats with chemotherapyinduced ovarian damage. Cytotherapy 10(4):353-363. doi:10.1080/14653240802035926.

Gilchrist RB. 2011. Recent insights into oocyte - follicle cell interactions provide opportunities for the development of new approaches to in vitro maturation. Reprod Fertil Dev. 23(1):23. doi:10.1071/RD10225.

Hull KL, Harvey S. 2014. Growth hormone and reproduction: A review of endocrine and autocrine/paracrine interactions. Int J Endocrinol. 2014:1-24. doi:10.1155/2014/234014.

Jin JX, Lee S, Khoirinaya C, Oh A, Kim GA, Lee BC. 2016. Supplementation with spermine during in vitro maturation of porcine oocytes improves early embryonic development after parthenogenetic activation and somatic cell nuclear transfer1. J Anim Sci. 94(3):963970. doi:10.2527/jas.2015-9761.

Kranc W, Budna J, Chachuła A, Borys S, Bryja A, Rybska M, Ciesiółka S, Sumelka E, Jeseta M, Brüssow KP, Bukowska D, Antosik P, Bruska M, Nowicki M, Zabel M, Kempisty B. 2017. “Cell migration” is the ontology group differentially expressed in porcine oocytes before and after in vitro maturation: a microarray approach. DNA Cell Biol. 36(4):273-282. doi:10.1089/dna.2016.3425.

Machtinger R, Laurent LC, Baccarelli AA. 2016. Extracellular vesicles: roles in gamete maturation, fertilization and embryo implantation. Hum Reprod Update 22(2):182-193. doi:10.1093/humupd/dmv055.

Overman J, Helder M, ten Bruggenkate C, Schulten E, Klein-Nulend J, Bakker A. 2013. Growth factor gene expression profiles of bone morphogenetic protein-2treated human adipose stem cells seeded on calcium phosphate scaffolds in vitro. Biochimie 95(12):23042313. doi:10.1016/j.biochi.2013.08.034. 
Pandey AC, Semon JA, Kaushal D, O'Sullivan RP, Glowacki J, Gimble JM, Bunnell BA. 2011. MicroRNA profiling reveals age-dependent differential expression of nuclear factor $\mathrm{kB}$ and mitogen-activated protein kinase in adipose and bone marrow-derived human mesenchymal stem cells. Stem Cell Res Ther. 2(6):49. doi:10.1186/scrt90.

Pereira G, Lorenzo P, Carneiro G, Ball B, BilodeauGoeseels S, Kastelic J, Pegoraro L, Pimentel C, Esteller-Vico A, Illera J, Granado G, Casey P, Liu I. 2013. The involvement of growth hormone in equine oocyte maturation, receptor localization and steroid production by cumulus-oocyte complexes in vitro. Res Vet Sci. 95(2):667-674. doi:10.1016/j.rvsc.2013.06.024.

Pomini Pinto RF, Fontes PK, Loureiro B, Sousa Castilho AC, Sousa Ticianelli J, Montanari Razza E, Satrapa RA, Buratini J, Moraes Barros C. 2015. Effects of FGF10 on bovine oocyte meiosis progression, apoptosis, embryo development and relative abundance of developmentally important genes in vitro. Reprod Domest Anim. 50(1):84-90. doi:10.1111/rda.12452.

Ra JC, Shin IS, Kim SH, Kang SK, Kang BC, Lee HY, Kim YJ, Jo JY, Yoon EJ, Choi HJ, Kwon E. 2011. Safety of intravenous infusion of human adipose tissue-derived mesenchymal stem cells in animals and humans. Stem Cells Dev. 20(8):1297-1308. doi:10.1089/scd.2010.0466.

Saadeldin IM, Kim SJ, Choi YB, Lee BC. 2014. Improvement of cloned embryos development by co-culturing with parthenotes: a possible role of exosomes/microvesicles for embryos paracrine communication. Cell Reprogram 16(3):223-234. doi:10.1089/cell.2014.0003.

Scruggs BA, Semon JA, Zhang X, Zhang S, Bowles AC, Pandey AC, Imhof KM, Kalueff AV, Gimble JM, Bunnell BA. 2013. Age of the donor reduces the ability of human adipose-derived stem cells to alleviate symptoms in the experimental autoimmune encephalomyelitis mouse model. Stem Cells Transl Med. 2(10):797-807. doi:10.5966/sctm.2013-0026.

Setyawan EMN, Kim MJ, Oh HJ, Kim GA, Jo YK, Lee SH, Choi YB, Lee BC. 2016. Spermine reduces reactive oxygen species levels and decreases cryocapacitation in canine sperm cryopreservation. Biochem Biophys Res Commun. 479(4):927-932. doi:10.1016/j.bbrc.2016.08.091.

Shimada M, Hernandez-Gonzalez I, Gonzalez-Robayna I, Richards JS. 2006. Paracrine and autocrine regulation of epidermal growth factor-like factors in cumulus oocyte complexes and granulosa cells: key roles for prostaglandin synthase 2 and progesterone receptor. Mol Endocrinol. 20(6):1352-1365. doi:10.1210/me.2005-0504.

Son YJ, Lee SE, Hyun H, Shin MY, Park YG, Jeong
SG, Kim EY, Park SP. 2017. Fibroblast growth factor 10 markedly improves in vitro maturation of porcine cumulus-oocyte complexes. Mol Reprod Dev. 84(1):67-75. doi:10.1002/mrd.22756.

Toori MA, Mosavi E, Nikseresht M, Barmak MJ, Mahmoudi R. 2014. Influence of insulin-like growth factor-I on maturation and fertilization rate of immature oocyte and embryo development in NMRI mouse with TCM199 and $\alpha$-MEM medium. J Clin Diagn Res. 8(12):AC05-08. doi:10.7860/JCDR/2014/9129.5242.

Uzumcu M, Pan Z, Chu Y, Kuhn PE, Zachow R. 2006. Immunolocalization of the hepatocyte growth factor (HGF) system in the rat ovary and the anti-apoptotic effect of HGF in rat ovarian granulosa cells in vitro. Reproduction 132(2):291-299. doi:10.1530/rep.1.00989.

Wilson A, Shehadeh LA, Yu H, Webster KA. 2010. Agerelated molecular genetic changes of murine bone marrow mesenchymal stem cells. BMC Genomics 11:229. doi:10.1186/1471-2164-11-229.

Woods DC, Tilly JL. 2012. The next (re)generation of ovarian biology and fertility in women: is current science tomorrow's practice? Fertil Steril. 98(1):3-10. doi:10.1016/j.fertnstert.2012.05.005.

Wu W, Niklason L, Steinbacher DM. 2013. The effect of age on human adipose-derived stem cells. Plast Reconstr Surg. 131(1):27. doi:10.1097/PRS.0b013e3182729cfc. 